This item was submitted to Loughborough's Research Repository by the author.

Items in Figshare are protected by copyright, with all rights reserved, unless otherwise indicated.

\title{
Attitudes towards earth building for Zambian housing provision
}

PLEASE CITE THE PUBLISHED VERSION

PUBLISHER

(C) Thomas Telford Publishing

LICENCE

CC BY-NC-ND 4.0

\section{REPOSITORY RECORD}

Hadjri, Karim, Mohamed Osmani, Bousmaha Baiche, and Charles Chifunda. 2019. "Attitudes Towards Earth Building for Zambian Housing Provision”. figshare. https://hdl.handle.net/2134/3793. 
This item was submitted to Loughborough's Institutional Repository (https://dspace.lboro.ac.uk/) by the author and is made available under the following Creative Commons Licence conditions.

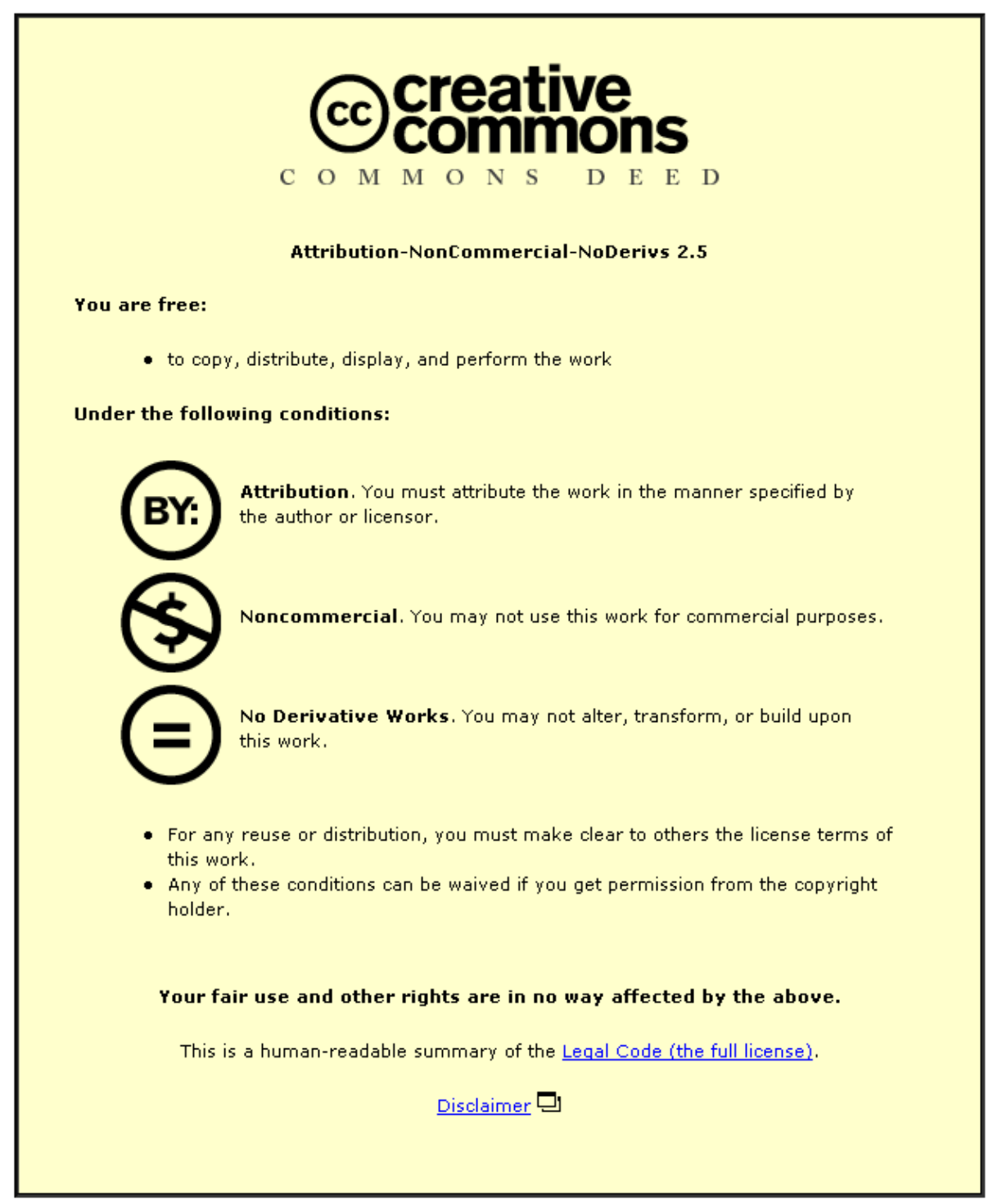

For the full text of this licence, please go to: http://creativecommons.org/licenses/by-nc-nd/2.5/ 


\section{Attitudes towards earth building for Zambian housing}

\section{provision}

K. Hadjri, DipArch, MPhil, PhD, M. Osmani, DipArch, MPhil, B. Baiche, DipArch, MPhil, PhD and C. Chifunda MSc

Zambian cities are experiencing a massive influx of people from rural areas resulting in high demand for housing and the growth of squatter settlements. Insufficient use of low-cost traditional construction techniques in the Zambian residential construction industry has resulted in expensive housing stock for the majority of the poor. There is therefore an urgent need to assess alternative building materials and techniques that are both affordable and sustainable. This research examines the viability of earth as a building material and associated construction techniques for urban housing provision in Zambia. Attitudes towards earth building among end-users, designers, contractors and government regulators were assessed using quantitative and qualitative research approaches. The study concludes that urban residents associate earth houses with poverty and low socio-cultural status; construction professionals are reluctant to specify and select earth materials due to their technical and performance limitations; and government regulators acknowledged that there are currently no appropriate earth building standards and codes in place. Nevertheless, Zambian designers and contractors expressed their willingness to use the material if its performance is improved. Furthermore, government reported that new codes of practice and standards could be developed if stimulated by research findings.

\section{INTRODUCTION}

Over recent decades, world awareness of the need for appropriate housing for the poor has grown and has now become a priority of many international non-government organisations (NGOs), charities and governments. However, appropriate construction solutions and the use of readily available traditional building materials such as earth have made no noticeable impact on the housing shortage. Partly as a result, the number of homeless people worldwide passed 100 million. ${ }^{1}$ Rapid urbanisation and increasing migration from rural areas has led to dramatic transformations of Zambian cities. ${ }^{2}$ Indeed, Zambia is one of the most urbanised countries in Africa with over $40 \%$ of people living in urban areas, of which 74\% live in slums. ${ }^{3}$ The provinces of Lusaka and Copperbelt (Fig. 1) have the largest percentage urban populations ( $82 \%$ and $81 \%$ respectively). ${ }^{4,5}$
According to the last national census conducted in the year 2000, Zambia had a total population of 9.9 million and near 1.8 million existing housing units. ${ }^{4}$ Conventional houses in Zambian urban areas constitute $64 \%$ of total housing units; traditional houses (indigenous to a particular village irrespective of building materials) including earth buildings form $14 \%$ of the total and the rest are a mixture of other residential units such as mobile houses and living quarters embedded in residential buildings. ${ }^{4}$ By contrast, $86 \%$ of the rural housing stock is traditional and only $8 \%$ is conventional. Overall, in $2000,62.4 \%$ of the total stock were traditional housing units and $30 \cdot 6 \%$ were conventional. ${ }^{4}$ Furthermore, the average household size in urban areas is 5.5 persons ${ }^{6}$ and $55 \%$ of the population live in one-bedroom housing units. ${ }^{4}$ This situation has been exacerbated by the continuous massive drift of people from rural areas, resulting in a high demand for urban housing and the growth of squatter settlements in the outskirts of Zambian cities and towns. ${ }^{7}$ Moreover, housing construction with conventional materials is too expensive for the majority in urban areas where transport amounts to about $40 \%$ of the material cost. $^{8}$

Zambia presents an interesting case study given the urgent need for low-cost urban housing, the historical use of earth building in rural areas, and the lack of dissemination of studies on traditional construction technologies and their potential to deliver affordable and durable housing. ${ }^{9}$ The need for suitable low-cost housing remains a priority for the Zambian Government. ${ }^{10}$ The means by which the housing shortage will be alleviated is, however, unclear.

This research investigates the potential of earth building to deliver affordable and durable housing in Zambia with the aim of

(a) examining performance criteria and construction techniques of earth

(b) reviewing earth building initiatives in Africa

(c) capturing end users' views on living conditions in earth houses

(d) assessing designers' and contractors' perceptions and attitudes to earth building

(e) investigating the current Zambian Government's initiatives and codes of practice to promote the use of earth in the construction industry. 


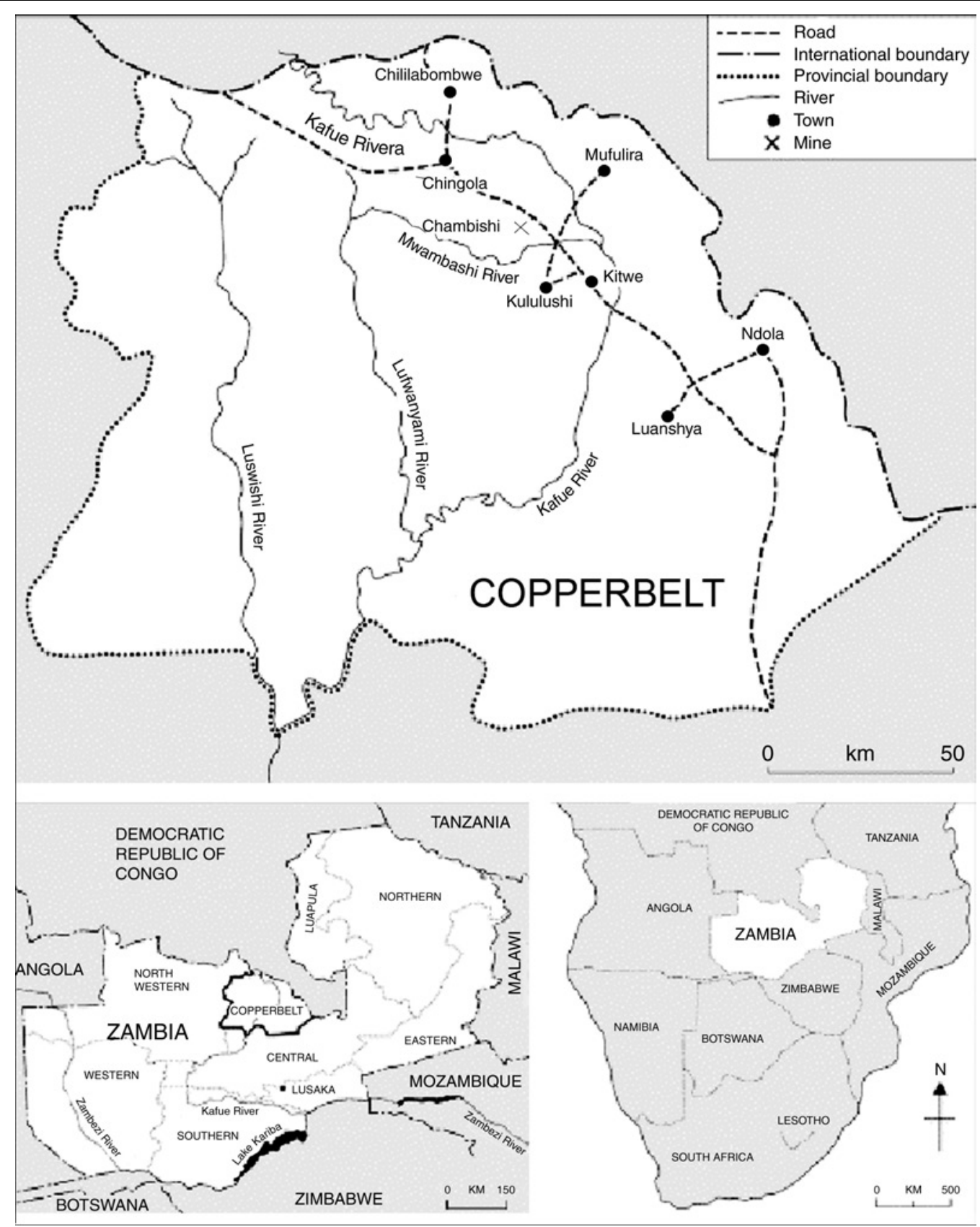

Fig. I. Location of Zambia and the Copperbelt province (after Von der Heyden and New ${ }^{5}$, C Elsevier)

Finally, the paper provides a platform for further research and open debate on earth construction through a set of recommendations.

\section{EARTH BUILDING}

Earth construction techniques have been known for millennia; even today one third of mankind lives in earth buildings. ${ }^{11}$ In the past, earth was the predominant building material in hot dry climates due to its indoor environmental benefits over conventional building materials such as concrete blocks. ${ }^{11}$ The revival of earth construction in many parts of the world has been encouraged by rising energy costs that impact strongly on building materials such as cement and fired bricks. ${ }^{12}$ Experience has shown that earth remains a viable material, given costly increases in energy consumption caused by the production of modern building materials. ${ }^{13,14}$ Agarwal $^{13}$ and Doat et al. ${ }^{15}$ went further to report that the appropriate use of earth construction produced cost-effective and comfortable buildings. Additionally, several international institutions, such as CRATerre, Earth-Auroville and Cal-Earth, have been created to develop and disseminate knowledge of the use of earth as a building material and associated construction techniques, particularly for housing. ${ }^{15-17}$ These organisations exchange information and experience, raise public awareness of the benefits of this material and inform public authorities of the need to consider and utilise appropriate construction materials and technologies. ${ }^{18,19}$

\section{I. Earth properties and construction techniques}

As shown in Table 1, earth has a number of financial and environmental attributes-it is fire resistant, has good thermal and sound insulation properties, balances humidity and absorbs pollutants. ${ }^{15,18}$ Furthermore, Dobson's ${ }^{20}$ findings, emanating from 11 case studies, showed earth structures have lower 


\begin{tabular}{ll}
\hline Advantages & \multicolumn{1}{c}{ Disadvantages } \\
\hline Availability & Durability \\
Versatility & Maintenance \\
Low-cost/affordability & Socio-cultural perception \\
Low environmental impact & Structural limitations \\
Fire resistance & Water absorption \\
Excellent control of indoor air & Low resistance to abrasion \\
moisture & and impacts \\
Low embodied energy & Specialist skills needed for \\
& plastering \\
High thermal capacity & \\
Low thermal conductivity* & \\
Good sound insulation & \\
properties & \\
Highly recyclable & \\
Easy workability & \\
Easy to design with & \\
\hline
\end{tabular}

*The thermal performance of a compressed or rammed earth wall depends on its density, porosity and water content.

Nevertheless, results from some research projects in the USA and UK have shown that, overall, the thermal performance of adobe and rammed earth is much better than that of common clay brick, limestone and dense concrete. ${ }^{13}$

Table I. Advantages and disadvantages of earth as a building material

embodied energy than buildings made from conventional materials. Similarly, Baggs ${ }^{21}$ reported that a $250 \mathrm{~mm}$ thick compressed earth wall has an embodied energy 23 times less than an equivalent $270 \mathrm{~mm}$ double skin clay-fired brick. In addition to energy savings at the production stage, unbaked earth buildings also require less heating and cooling-earth walls ensure substantial reductions in heat losses and a general feeling of 'thermal comfort'. ${ }^{22-25}$ Additionally, earth is versatile and can be used to reflect architectural diversity; it also offers a means of providing easily extendable or altered housing for all types of households. ${ }^{13,26,27}$ On the other hand, a number of constraints (e.g. inability to resist adverse weather conditions and poor water resistance) impede its wider adoption (Table 1). These limiting factors are exacerbated by low resistance to wear and tear, poor compressive and tensile strength, and high susceptibility to mechanical damage. ${ }^{28-32}$

However, although earth buildings are highly susceptible to damage by water action, various solutions have been developed over centuries and many other modern processes have recently been perfected. The effect of water on earth buildings can be greatly reduced by taking a variety of preservative measures depending on local climate and rainfall conditions. ${ }^{13}$ The use of a chemical additive such as 'mortar-proof' (which is quite inexpensive) to inhibit water absorption in render, at least in splash zones externally, is one good option. The design of earth dwellings is also an important factor. Generally, an earth dwelling needs 'a good hat and a pair of shoes', meaning an overhanging roof to protect the walls from rain, and stone or concrete foundations raised above ground to make the plinth wall, which should protect the bottom part of the walls from running water and rising humidity. In addition, there may be a need for a damp-proof course of some type on top of the plinth wall to protect the earth wall against moisture rise..$^{23,31,33}$
Earth constructions tend to have low tensile strength (i.e. they are easy to pull apart) meaning that earth roofs are difficult to make, except by using vaults, as the ancient Nubians did. Earth construction also has a tendency to have poor load-bearing capacity making it unsuitable for supporting roofs on large-span buildings. Given its low tensile strength, an earth wall must be thick otherwise it could not remain standing, but would rather lean, bend and collapse. In contrast, walls built of concrete tend to be thin. This is structurally possible since the tensile stresses typical of any concrete wall are taken by steel reinforcements either in the wall itself or, more often, by a framework of reinforced concrete or steel columns and beams within which the wall is simply a thin panel infill. These, however, can prove to be expensive methods of construction. It is interesting to note that wattle and daub is an earth construction technique consisting of a load-bearing structure (commonly a wooden frame in the form of a lattice of wooden poles tied or nailed together) and a support of wickerwork or plaited twigs. Clay soil, mixed with straw, local vegetable fibres or other additives, is then daubed on either side of the laths which act as reinforcement. ${ }^{13,23,26,34}$ In many modern earth buildings, stone, timber and/or steel reinforcements have been used in different parts of the buildings, for example in lintels, collar beams, corners and between courses..$^{33,35,36}$

Earth construction is mainly used for walling. At least 20 different traditions of earth walling techniques are known, but three predominate-pisé or rammed earth, adobe and compressed earth bricks. ${ }^{13}$ Building methods are chosen based on climate, ease of use and locally available materials, and the priority given to different factors varies with the socio-cultural structure of the community. ${ }^{37}$

(a) Pisé de terre (or rammed earth) consists of earth masonry containing a relatively high proportion of gravel and little additional moisture, rammed manually between two shutters (vertical frameworks) on either side of the wall. ${ }^{12,34-40}$

(b) Adobe is a sun-dried mud brick, produced in different shapes and sizes using bottomless wooden moulds and compacted slightly by hand. Adobe's stability can be enhanced by adding straw, cow dung or even bitumen. The terms sun-dried brick, unburnt brick, unbaked brick, unfired brick, puddled earth, mud wall and mud brick are used by many authors as equivalents to adobe. ${ }^{13,30,32,33,38,41,42}$

(c) Compressed earth brick is the modern version of the unbaked and moulded brick. It uses earth with similar characteristics to those of pisé but with higher clay content (up to 25\%) and less gravel. Slightly wet soil is compacted in presses of diverse types that vary widely in efficiency. Nevertheless, the process of making compressed earth bricks takes much longer than adobe, remains dependent on expensive equipment and requires delicate handling when cast. ${ }^{33,41,43,44}$

Despite having a long and acceptable history in architecture, many associate earth use with poverty and under-development. ${ }^{33}$ Norton ${ }^{45}$ goes further, reporting that zoning regulations either indirectly or directly preclude the use of earth for building in many towns and cities in Zambia, making planning permission difficult. Conversely, countries like Australia, ${ }^{46}$ New Zealand ${ }^{47-49}$ and the USA ${ }^{50}$ have developed new codes and put in place regulations and guidance for earth building. Additionally, recent 
research into the use of earth building material is allowing the construction of stronger, versatile, more durable and socially acceptable buildings. ${ }^{51}$ It is interesting to note that similar efforts are being invested in the revival of earth building in Africa, as examined in the next section.

\subsection{Earth building in Africa}

Conventional construction methods, including the use of burnt bricks and cement products such as concrete, have been the recent norm for building worldwide. The same applies to Zambia, yet $80 \%$ of Zambia's rural dwellings are made of unburnt brick ${ }^{4}$ and walls are made of sun-dried bricks and wattle and daub, composed of clay-rich soil without straw or fibre reinforcement. Moreover, Denyer ${ }^{52}$ recognised that Zambia has very good soils for building purposes. However, Sojkowski ${ }^{53}$ reported that there is a widespread socio-cultural perception in Zambia that modern building techniques and materials are substantially better than traditional ones.

Similar situations exist in other parts of Africa such as Nigeria where, as a result, experiments to improve the durability and affordability of earth building have been undertaken, and earth building has been promoted as an alternative for low-cost housing for the poor. ${ }^{54}$ Furthermore, Adam and Agib ${ }^{55}$ reported that compressed stabilised earth blocks were successfully used for low-income housing in Sudan. The same study also presented approaches to promoting the use of earth in construction, including advertisements of earth block properties, pilot projects, research and development, training programmes and demonstration projects for home owners. The potential of earth building in Botswana has also been studied in order to develop a suitable material mix for a pressed earth block and forward recommendations on proportions of block mix, mixing methods, stabilisation, strengthening and transportation. ${ }^{56}$ The study concluded that further work is required to establish wider usage of earth blocks and encouraged earth block use for housing in Botswana, Namibia and Zimbabwe, which have soils similar to those found in Botswana. ${ }^{56}$ A pilot project on earth architecture, undertaken in Uganda to promote traditional earth building, forwarded recommendations to promote training at all levels, carry out pilot and demonstration projects, and undertake research on local construction materials and skills. ${ }^{16}$ Uganda has experienced barriers to earth building such as the need for new legislation, technical training, public awareness of sustainability and knowledge sharing. ${ }^{16}$

Based on these experiences, earth building can be promoted as a potential alternative for low-cost and affordable housing in Zambian urban areas. For Zambia to benefit from the experience of other African countries, the perceptions and attitudes towards earth building of Zambian stakeholders (end-users, designers, contractors and government regulators) must be identified. Practical barriers to the implementation and use of earth building should also be identified. This will enable design of a strategy to address social perceptions, improve the technical properties of earth-built structures and develop associated building standards and codes.

\section{METHODOLOGY}

Quantitative and qualitative research approaches were used in this study as a means of data collection to assess attitudes towards earth building among end-users, designers, contractors and government regulators. Three research methods were adopted. (a) A case study was carried out to gain insight into users' views on living conditions in earth houses. Qualitative information was collected through surveys and semi-structured interviews with 20 residents from two selected sites-earth homesteads in Nkana and conventional buildings in the Riverside area of Kitwe (Fig. 1). Kitwe, which includes a number of townships and suburbs including Nkana, is the third-largest town in Zambia. This case study provided the basis for formulation of the questionnaire.

(b) A questionnaire was used to collect data for a baseline overview of the Zambian construction industry's attitudes to earth construction. Sixty questionnaires were randomly distributed to architects, structural engineers and contractors specialising in housing. The questionnaire was divided into four sections-background information, sustainability within the company, specification/selection of building materials (including earth) and barriers to the widespread practice of earth construction. To address the aims of this paper, the focus of data analysis from the questionnaire results was two-fold. Firstly, to capture designers' and contractors' perspectives on key design and to formulate acceptable criteria that would influence the specification and selection of earth as a building material and associated construction techniques. Secondly, to assess their views on the limiting factors that hinder the use of earth in the Zambian construction industry. The two key issues were investigated through rating scale questions, calling for informants to assign an appropriate rating using the five-point Likert scale from 1 (lowest level) to 5 (highest level) to reflect their views on the importance of the listed variables.

(c) A semi-structured interview was conducted with the assistant standards inspector from the Zambian Bureau of Standards (ZABS). The aims of this research method were to: establish the Zambian Government's position on earth construction planning and compliance requirements; examine regulators' and policy makers' stand on earth as an alternative building material to alleviate the shortage of housing; and assess government's role in promoting the use of earth in construction.

The combination of the three methodologies helped reveal a broader view of how earth building is perceived by stakeholders in the Zambian construction industry and identify the hurdles facing its potential use for building developments in urban areas.

\section{RESULTS AND ANALYSIS}

\section{I. End users' perspectives}

It was observed during fieldwork that most traditional houses, mainly in rural areas, were generally rectangular, L-shaped, square or circular. Sun-dried earth bricks, wattle and daub, and clay content soil mortar were the most commonly used materials in the construction of dwellings visited during the case study. In a few cases, cement was added to the mixture to enhance adhesive strength. Internal walls were generally plastered with clay; a variety of tinted finishes were used depending on the colour of clay used (Fig. 2). Externally, cement and sand plaster were also used as rendering finishes and walls were left in grey cement or painted to a colour of the owner's preference (Fig. 3). 


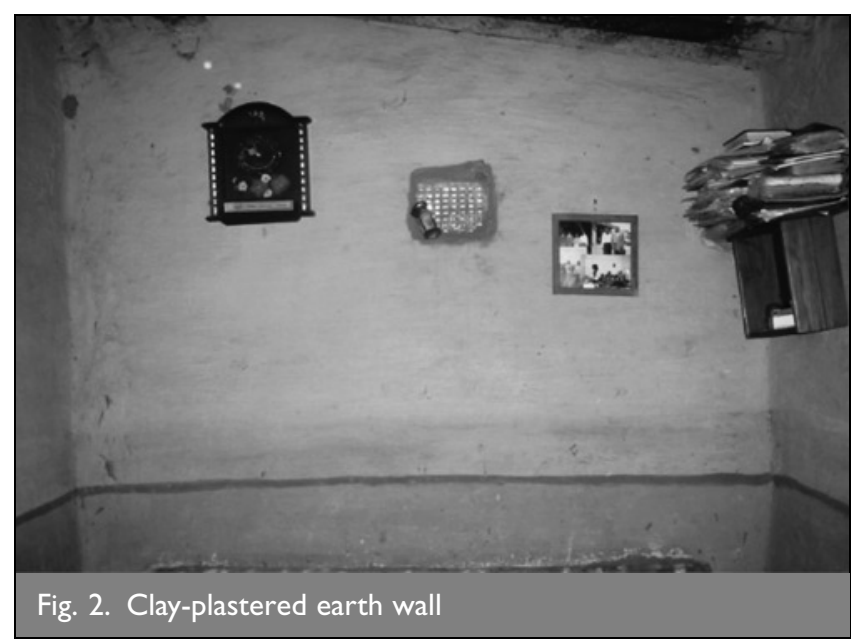

Interviewees reported that their houses had a life span of about 25 to 30 years.

Ten residents living in rural earth-constructed houses were interviewed about five key issues: durability; affordability; living conditions; aesthetics; and their general preference with regard to living in an earth dwelling rather than a 'modern' house.

(a) Durability. Half of the interviewees said their houses were durable, lasting more than 20 years; the other half reported a dwelling life span of less than 10 years, requiring regular maintenance. The latter category identified two major problems-rainwater washing away walls and foundations, and termite damage.

(b) Affordability. All interviewees agreed that earth dwellings were very affordable in comparison with houses built with conventional materials.

(c) Living conditions. Eight interviewees acknowledged that living in an earth-built house was very comfortable, offering a very good thermal environment. They went further by stating that a house roofed with thatch is even more comfortable, presenting occupants with a well-humidified and thermally regulated interior. Conversely, the remaining two indicated that their houses tended to be very hot in summer and very cold in winter. This was mainly due to the fact that their houses were roofed with corrugated iron sheets and had no ceiling. Heat transmission was therefore excessive, creating an uncomfortable environment in winter and summer.

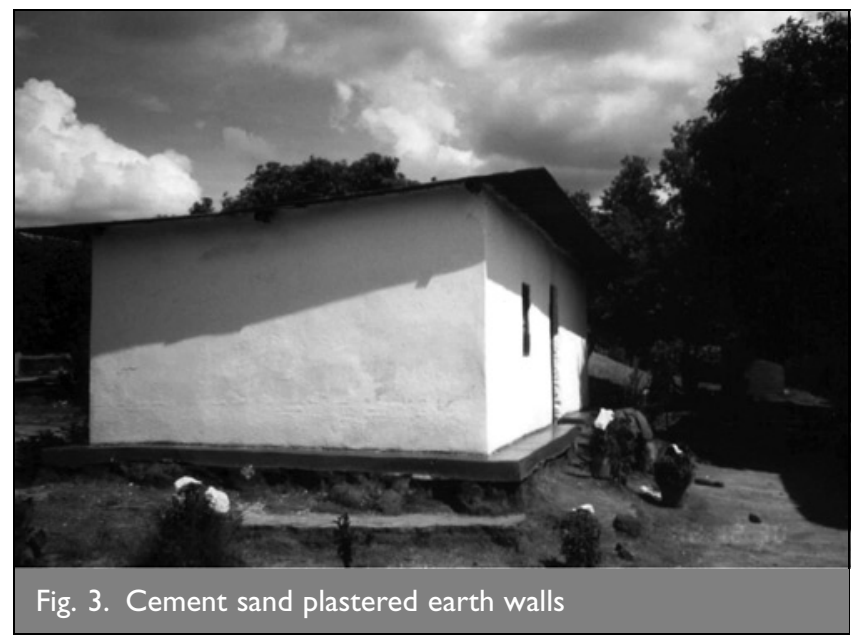

(d) Aesthetics. Four interviewees did not like the appearance of earth-built houses; two were indifferent; and the remaining four liked the different colour effects of clay as a façade finish. Furthermore, when plastered with cement sand plaster, paints of various colours could be used, thus giving scope for a range of decorative surface renderings.

(e) General preference. Given financial resources, seven interviewees reported that they would not live in earth houses as these are culturally associated with poverty and low social class. It is interesting to note, however, that a third of residents agreed that they would live in earth houses, provided construction methods and finishes are improved.

Ten people living in urban conventional medium- to high-cost houses in Riverside were asked if they would consider buying or renting an earth house. All interviewees said they would not be willing to live in or own an earth-built house because it was a symbol of low societal status. Additionally, they perceived earth houses as unattractive in appearance and not durable, and concurred that poor design and construction standards are major disincentives.

\subsection{Designers' and building contractors' perspective}

Of the 60 questionnaires circulated to design practices and contracting companies, 22 were completed, representing a response rate of 37\%. Responses from the survey were analysed using the Statistical Package for Social Sciences (SPSS) by generating means and frequencies. Analysis of the five-point Likert scale answers was carried out by comparing the means. The majority of respondents said they undertook more residential projects than any other category of building types. Sustainable practices were not very common amongst responding consultants and contractors, and none had a sustainability policy in place. Conventional materials were commonly used, while traditional building materials were scarcely employed. Indeed, 73\% of respondents never used earth in their projects. There was, however, a strong indication of potential use in the future, as long as technical weaknesses were adequately addressed. Additionally, the respondents recognised that the government has a major role to play by taking deliberate steps to promote earth construction and regulate its use.

Respondents were asked to rate a range of criteria for potential specification and selection of earth as a building material in their projects against a five-point Likert scale. The results, shown in Fig. 4, indicate that 'material cost' was accorded the highest mean importance rating (4.58), followed closely by availability $(4 \cdot 37)$ and easy workability $(4 \cdot 11)$.

Informants were asked to rate a number of limiting factors that impede the use of earth in the Zambian construction industry. As shown in Fig. 5, the majority (69\%) strongly believed that structural weakness (mean value of 4.50) was the key constraint in specifying earth in their projects, followed closely by lack of interest by clients (mean value of $4 \cdot 31$ ). Additionally, respondents rated equally (mean value 3.50 ) lack of technical knowledge on earth construction and the perception of earth as not suitable in upmarket developments as critical barriers. Similarly, poor water resistance and the perception by society of 


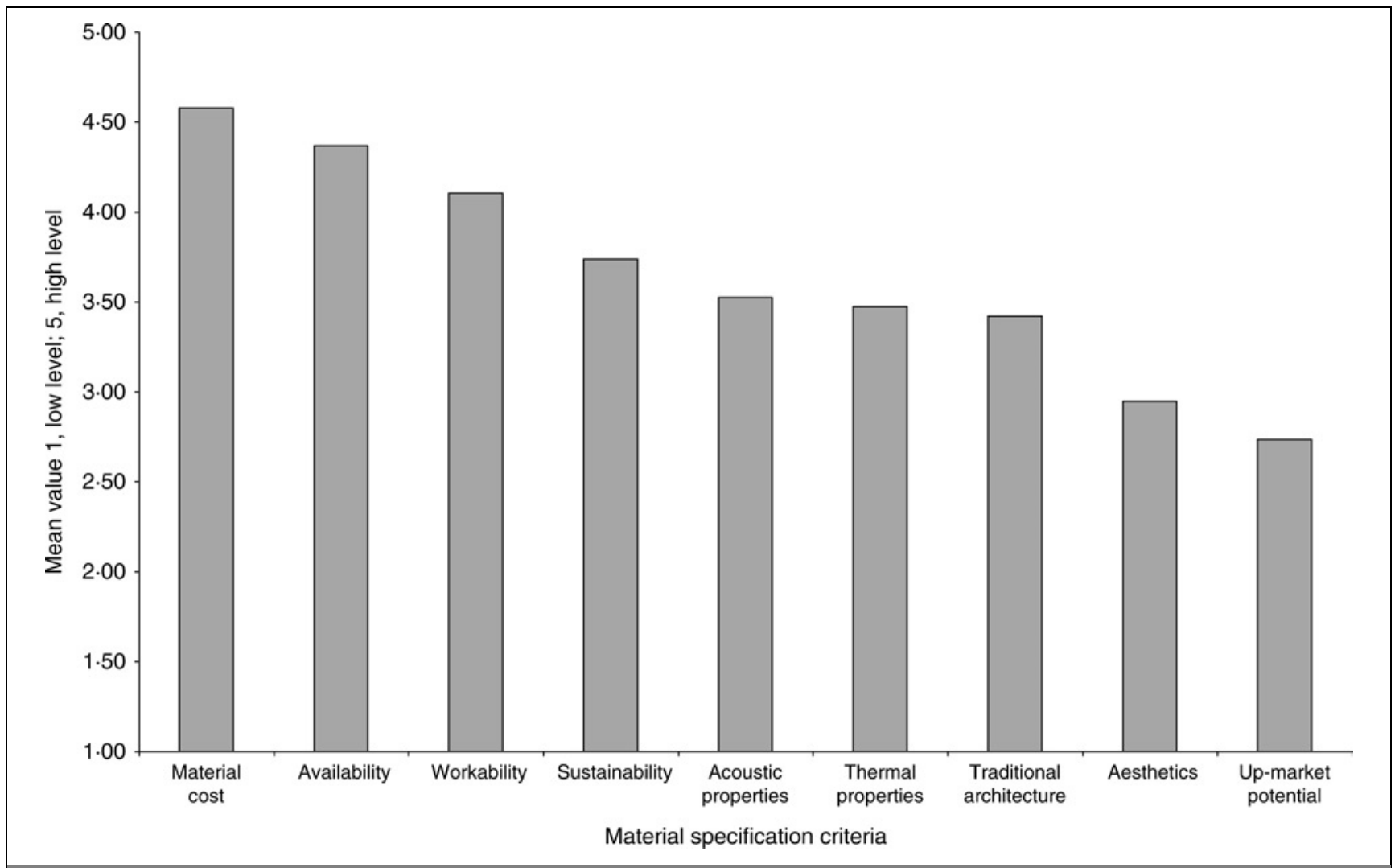

Fig. 4. Factors influencing the specification of earth in the Zambian construction industry

earth as a sign of unattractive old architecture were seen as serious impediments to its wider use.

Figures 4 and 5 clearly illustrate the challenges faced by earth construction in Zambia. These are valuable pointers to the formulation of recommendations for the construction industry and government.

\subsection{Government's perspective}

A semi-structured interview, based on the findings of the questionnaire and end users' interviews, was conducted with the assistant standards inspector from the ZABS. The interview protocol included: sustainability and traditional materials; building standards for sun-dried earth; construction planning issues and training; potential of earth building to overcome

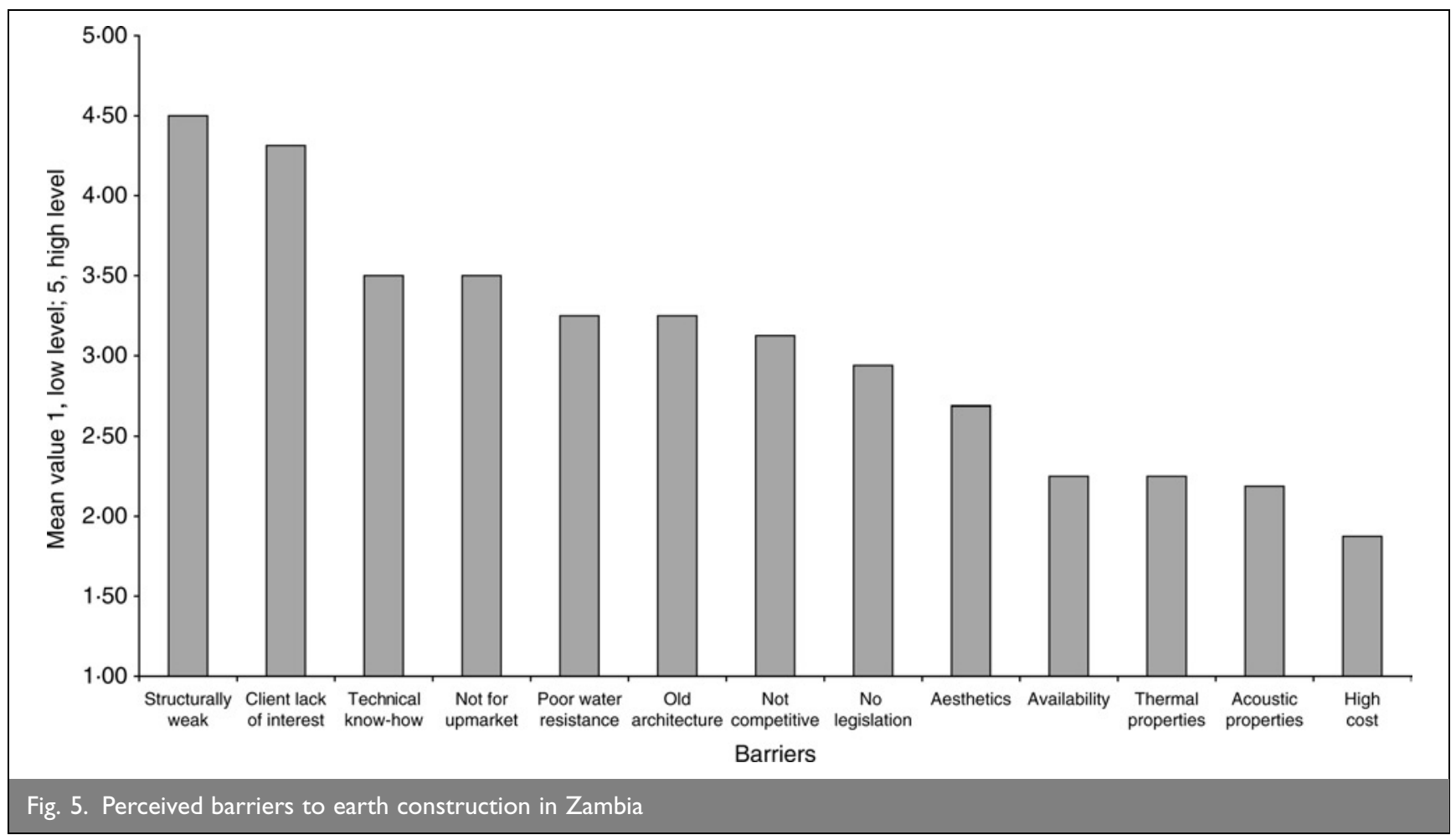


housing shortages in urban areas. The results of the interview are summarised below.

(a) Sustainable building is not common practice in the Zambian construction industry. The ZABS official argued that this is probably due to lack of adequate infrastructure, which has not reached a high level and therefore there is a general laxity in the implementation of sustainability.

(b) The ZABS currently has no building standards for earth construction.

(c) There is currently no vocational training on working with earth building materials.

(d) Planning restrictions do not allow the use of ordinary sundried bricks in urban areas. It is interesting to note that ZABS considers all settlements built with sun-dried bricks, usually on the outskirts of cities, as squatter settlements or slums and, as such, as illegal developments. However, the ZABS official acknowledged that if earth is stabilised or compressed, the authorities have no objection to its use. On the other hand, he reported that the use of earth is encouraged for safari lodges and similar tourist-oriented structures. Therefore planning authorities have no objection to granting permission for such developments.

\section{DISCUSSION}

The rapid urban expansion of Zambian cities has led to an alarming growth of slums, where $74 \%$ of the urban population live in informal settlements. This proportion is set to increase as the urban population increases, unless critical issues of housing provision are adequately addressed.

A literature review revealed that earth as a building material and associated construction techniques appears to offer a viable alternative that can effectively and cheaply reduce the housing shortage in Zambia's urban areas. However, a number of barriers need to be addressed before earth building can be embraced by the Zambian construction industry, regulators and end-users.

The case study showed that earth buildings are perceived as not durable and aesthetically unpleasant. Furthermore, they are regarded as a sign of poverty and backwardness. However, earth buildings offer good indoor conditions, maintain pleasant thermal comfort and are affordable by the majority of the poor. Additionally, designers and contractors were reluctant to specify and select earth materials due to their technical problems and performance limitations. Indeed, the use of earth building materials and techniques is not a high priority during design and construction. Nonetheless, there was consensus amongst construction professionals that earth has potential due to its cost effectiveness, availability, ease of workability and positive impact on the environment (particularly its low embodied energy and positive contribution to resource efficiency).

Mususa and Wood $^{9}$ explored the creation of a sustainable building industry to deliver low-cost urban housing in Lusaka, the capital city of Zambia, by investigating the development approach and main social housing policies implemented in Zambia since $1965 .{ }^{9}$ They identified 'dynamic pressures', that is, governmental modernisation strategies and support for concrete building technology, favouring the use of concrete over more readily available materials such as earth.
Likewise, a study by Mukalula ${ }^{57}$ found that rural communities have used burnt bricks that had been poorly fired and as a result lacked durability; there were no 'quality monitoring mechanisms' to ensure sustainable construction and to alleviate poverty by producing decent durable housing. It was recommended that the Zambian Council for Construction should formulate policies for sustainable construction practices. $^{57}$

The Association of African Universities (AAS) ${ }^{58}$ carried out research on university-industry relationships and the transfer of appropriate technologies in particular within five African countries including Zambia. Although this AAS study targeted small and medium enterprises (SMEs) and did not consider the construction industry or earth building, it pointed out that Zambia 'has an explicit policy to promote partnership with SMEs on the one hand and universities and research institutions on the other'. Additionally, it concluded that although there have been some successful university-industry partnerships, links between the leading universities and industry are still weak ${ }^{58}$ and dissemination of work has not been implemented effectively ${ }^{9}$ particularly by universities in order, for example, to respond to the needs of SMEs. ${ }^{58}$ These findings should be taken into consideration for future university-industry partnerships, particularly those targeted at sustainable construction via earth building.

In Zambia there are barriers that impede the use of earth in the construction industry, for example the lack of earth building codes/standards and government initiatives. This was echoed by the findings of Mususa and Wood ${ }^{9}$ who reported that current building codes and regulations favour conventional methods and actually prevent the use of traditional materials such as earth. Similarly, Tyrell ${ }^{59}$ argued that, under pressure for modernisation, the Zambian Government has so far neglected the promotion of vernacular construction methods and materials.

Urban residents associated earth houses with poverty and low socio-cultural status. The latter aligns with the findings of Sojkowski ${ }^{53}$ who revealed that earth materials and techniques are perceived as 'substandard' or 'second class' while modern construction methods and materials are seen as 'civilised' or 'symbols of affluence'. This would suggest that the role of architects, engineers and building contractors could be very significant in influencing culture change and producing suitable earth-built housing by leading the debate, designing and constructing desirable earth dwellings, and offering confidence to developers and the public. However, the role of government is equally important in developing policies, codes of practice and training programmes to help building designers and contractors use earth materials and building techniques.

\section{CONCLUSIONS}

Insights into the current Zambian housing situation, assessment of earth properties and construction techniques, and stakeholders' perceptions and attitudes towards earth building in Zambia have been investigated in this research. Zambia still faces major issues concerned with perceptions and attitudes towards earth building on the one hand, and lack of technical knowledge and building codes on the other. 
The majority of interviewees would not consider living in earth houses. A number of social attitudes thus need to be addressed through publicity, public consultations and demonstration projects. Additionally, short courses and workshops would assist designers, contractors and developers to specify and use earth in housing projects. There is also a need for research and implementation of earth design and construction improvement techniques to address the limiting factors of aesthetics, performance and maintenance. Aware of this challenge, ZABS is willing to adopt new codes of practice and standards to promote the use of earth in construction. Nonetheless, national and international incentives and information sharing are needed to convince all parties of the advantages of earth as a viable building material. Key stakeholders in the Zambian construction industry could benefit from

(a) the establishment of knowledge-transfer partnerships with countries where earth building is standardised and successfully used

(b) thorough studies on affordability of earth construction

(c) the promotion of research into the design and performance of earth materials and construction techniques

(d) experiments on earth block stabilisation and manufacturing for low-cost housing

(e) the development of earth building codes and standards

$(f)$ the amendments of regulatory procedures to streamline planning permission for earth buildings

$(g)$ the formulation of national strategies to promote and spread the use of earth construction through publicity, research and development, training and pilot projects

(h) mechanisms for the implementation of national strategies, including training in earth construction at all levels (professional and vocational)

(i) the development of sustainability policies to encourage the use of earth as a building material.

\section{ACKNOWLEDGEMENTS}

We thank all the organisations and individuals in Zambia who participated in this research.

\section{REFERENCES}

1. HADJRI K. Experimenting with hybrid construction-guadua bamboo and adobe for housing in rural Colombia. International Journal for Housing Science and Its Applications, 2005, 29, No. 2, 165-177.

2. Silavwe G. W. Effects of rural-urban migration on urban housing in Zambia. Ekistics, 1994, 61, No. 366, 240-246.

3. UN-HABITAT. United Nations Human Settlements Programme, Zambia, Statistical Overview 2001 Estimates. See http://www.unhabitat.org/categories.asp?catid=243 for further details. Accessed 04/03/2007.

4. Central Statistics Office. Migration and Urbanisation: 2000 Census of Population and Housing. CSO, Lusaka, Zambia, 2003.

5. Von Der Heyden C. J. and New M. G. Groundwater pollution on the Zambian Copperbelt: deciphering the source and the risk. Science of the Total Environment, 2004, 327, Nos. 1-3, 17-30.

6. Chewe P. M. Characteristics of households and respondents. In Zambia: Demographic and Health Survey 2001-2002. Central Statistical Office, Lusaka, 2003, p. 102.
7. SCHLYTER N. Housing policy in Zambia. Habitat International, 1998, 22, No. 3, 259-271.

8. UNHCS (HABITAT). United Nations Centre for Human Settlements, Building Materials and Construction Technologies. Journal of the Network of African Countries on Local Building Materials and Technologies, 1990, 1, No. 2.

9. Mususa P. N. and Wood B. The Creating of a Sustainable Building Industry in the Housing Sector of Lusaka, Zambia, 2004. See http://buildnet.csir.co.za/cdcproc/docs/3rd/ mususa_wood.pdf for further details. Accessed 19/02/2007.

10. UN-HABITAT. United Nations Human Settlements Programme, Zambia, Country Report on the Implementation of the Habitat Agenda (Istanbul + 5), 2001. See http:// ww2.unhabitat.org/istanbul $+5 /$ Zambia.doc for further details. Accessed 08/03/2007.

11. Houben H. and Guillaud H. Earth Construction: A Comprehensive Guide. Intermediate Technology Publications, London, 1994, 6-10.

12. NGowi A. B. Improving the traditional earth construction: a case study of Botswana. Construction and Building Materials, 1997, 11, No. 7, 1-7.

13. Agarwal A. Mud, Mud: The Potential of Earth-Based Materials for Third World Housing. Earthscan, London, 1981.

14. Montgomery D. E. Dynamically-Compacted Cement Stabilised Soil Blocks for Low-Cost Walling. PhD thesis, University of Warwick, 2002.

15. Doat P., Hays A., Houben H., Matuk S. and Vitoux F. Building with Earth. The Mud Village Society, New Delhi, 1991.

16. CRATerre. Earth Architecture in Uganda: Pilot Project in Bushennyi 2002-2004. CRATerre-EAG, Grenoble, 2005, p. 34.

17. Houben H., Rigassi V. and Garnier P. Compressed Earth Blocks: Production Equipment. CRATerre-EAG, France, 1994.

18. Morton T., Stevenson F., Taylor B. and Charlton Smith N. Low Cost Earth Brick Construction. Arc Chartered Architects, Fife, 2005.

19. Viñuelas G. M., Martins Neves C. M., Flores M. O. and Silvio Rios L. Arquitecturas de Tierra en Iberoamérica. Programa de Ciencia y Tecnología para el Desarrollo, Centro Barro, Buenos Aires, Argentina, 1994.

20. Dobson S. Continuity of Tradition: New Earth Building. Report by the Joint Technical Committee of Standards Association of Australia and Standards New Zealand for preparation of a Standard for Earth Building for Australia and New Zealand. 2000. See http://www.dab.uts.edu.au/ ebrf/research/cont_tradition.html for further details. Accessed 19/01/2007.

21. BAGgS D. W. Future architecture trends with fewer building services. Journal of Geotecture International Association, 1992, 9, No. 2, 37-40.

22. Dethier J. Mud Architecture: An Old Idea, A New Future. Thames and Hudson, London, 1982.

23. Beazley E. and Harverson M. Living with the Desert: Working Building of the Iranian Plateau. Aris and Phillips. Warminster, 1982.

24. Evans M. Housing, Climate and Comfort. Architectural Press, London, 1980.

25. Fathy H. Natural Energy and Vernacular Architecture: Principles and Examples with Reference to Hot Arid Climates. University of Chicago Press, Chicago, 1986. 
26. KATEREgGA J. K. Improvement and use of earth construction products for low cost housing. In Appropriate Building Materials for Low Cost Housing, 1. F. N. Spon, London, 1983, pp. 23-33.

27. Еммот D. A Mud Revival. UN, New York, 1981, Development Forum No. 87

28. Yorulmaz M. Earthquakes and rural construction. Proceedings of Seminar Six in the Series, Architectural Transformations in the Islamic World, 1982, 1, 131-134.

29. Mulligan H. Back to the land. Building Design, 1987, No. 822, 14-15.

30. BADC (Information Service of the belgian Administration FOR DEVELOPMENT CO-OPERATION). Special issue, Building with earth. Dimension 3 Bimonthly Review, 1985, No. 4.

31. Shleifer S. A. Hassan Fathy's Abiquiu: an experimental Islamic educational center in rural New Mexico. Ekistics, 1984, 51, No. 304, 56-60.

32. GERMEN A. The endurance of earth as building material and the discreet but continuous charm of adobe. METU Journal of the Faculty of Architecture, 1979, 5, No. 1, 37-38.

33. CRATERre. Construire en Terre. Editions Alternatives et Paralleles, Paris, 1979.

34. Agarwal A. Research: mud as a traditional building material. Proceedings of Seminar Six in the Series, Architectural Transformations in the Islamic World, 1982, 1, 137-146.

35. MinKe G. Earth Construction Handbook. WIT Press, Southampton, 2000.

36. McHenry P. G. Adobe and the Rammed Earth Buildings: Design and Construction. University of Arizona Press, Tucson, 1989.

37. Spence R. J. S. and Coок D. J. Building Materials in Developing Countries. John Wiley, London, 1983, 21-22.

38. Clough W. E. Building in Cob, Pisé and Stabilized Earth. Country Life, London, 1947.

39. Jeannet J., Pignal B., Pollet G. and Scarato P. Le PiséPatrimoine-Restauration-Technique d'avenir. Editions CREER, Nonette, 1986.

40. Building Research Board Department of Scientific and Industrial RESEARCh. Building in Cob and Pisé. BRB, London, 1922, Special report No. 5, 19-35.

41. Guillaud H. Au début était la terre un matériau aux usages multiples. La Revue H, 1985, No. 111, 39-44.

42. Fullerton R. L. Building Construction in Warm Climates. Oxford University Press, London, 1968.

43. Houben H. and Verney P. E. Compressed Earth Blocks. Selection of Production Equipment. Centre for the Development of Industry, Brussels, 1989.

44. International Labour OfFice. Small-Scale Manufacture of Stabilised Soil Blocks. ILO, Geneva, 1987, Technical memorandum No. 12, p. 3.
45. Norton J. Building with Earth-A Handbook, 2nd edn. Intermediate Technology Publications, London, 1997.

46. Walker P. and Standards Australia. The Australian Earth Building Handbook-HB 195. Standards Australia International Limited, Sydney, 2002.

47. Standards New Zealand. NZS 4297: 1998 Engineering Design of Earth Buildings. See http://www.standards.co.nz/ default.htm for further details. Accessed 05/03/2007.

48. Standards New Zealand. NZS 4298: 1998 Materials \& Workmanship for Earth Buildings. See http:// www.standards.co.nz/default.htm for further details. Accessed 05/03/2007.

49. Standards New Zealand. NZS 4299:1998 Earth Buildings Not Requiring Specific Designs. See http:// www.standards.co.nz/default.htm. Accessed 05/03/2007.

50. Construction Industries Division of the Regulation And Licensing Department. Mexico Earthen Building Materials Code. CIDRLD, New Mexico, 2004, XV, 21.

51. Gooding D. E. and Thomas T. H. The Potential of Cement-Stabilised Building Blocks as an Urban Building Material in Developing Countries. Development Technology Unit, University of Warwick, 1995, DTU working paper no. 44.

52. DenYer S. African Traditional Architecture. Heinemann, London, 1978.

53. SoJkowski J. Zambian vernacular. See http:// www.architectureweek.com/2002/0807/culture_1-2.html for further details. Accessed 21/01/2007.

54. Оlотuah A. O. Recourse to earth for low-cost housing in Nigeria. Building and Environment, 2002, 37, No. 1, 123-129.

55. Adam E. A. and Agib A. R. A. Compressed Stabilised Earth Block Manufacture in Sudan. UNESCO, Paris, 2001.

56. LongFoot B. R. Earth Building in Botswana: Building Blocks Made From Kgalagadi Sand. See http:// www.dab.uts.edu.au/ebrf/research/botswana_1.html for further details. Accessed 19/01/2007.

57. Mukalula P. M. Poverty alleviation through the construction industry-the case of Zambia's rural areas. Proceedings of the 2nd LACCEI International Latin American and Caribbean Conference for Engineering and Technology: Challenges and Opportunities for Engineering Education, Research and Development, 2004, pp. 1-6. Available at http:// www.laccei.org/proceedings2004/FinalPapers/ST_072.pdf.

58. TARPEH D. N. University-Industry Relationships: Higher Education and Partnership with the Productive Sector and Service Sectors. See http://www.ciaonet.org/conf/nya01/ nya01bc.html for further details. Accessed 08/07/2007.

59. TyRell D. Prospects for Sustainable Human Development in Zambia: More Choices for our People. Government of the Republic of Zambia, Lusaka, 1996.

\section{What do you think?}

To comment on this paper, please email up to 500 words to the editor at journals@ice.org.uk

Proceedings journals rely entirely on contributions sent in by civil engineers and related professionals, academics and students. Papers should be $2000-5000$ words long, with adequate illustrations and references. Please visit www.thomastelford.com/journals for author guidelines and further details. 